
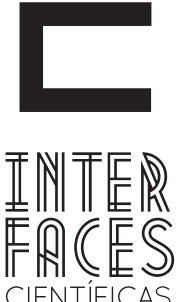

HUMANASE SOCIAIS

ISSN IMPRESSO 2316-3348

E-ISSN 2316-3801

DOI - 10.17564/2316-3801.2018v7n2p67-76

\title{
A DEMOCRACIA AUTORITÁRIA DA ERA VARGAS E AS CONCEPCC̄ÕES TEÓRICO-DEMOCRÁTICAS
}

THE AUTHORITY DEMOCRACY OF THE VARGAS ERA AND THEORETICAL-DEMOCRATIC CONCEPTIONS

LA DEMOCRACIA AUTORITARIA DE LA ERA VARGAS Y LAS CONCEPCIONES TEÓRICO-DEMOCRÁTICAS

Fernanda Gurgel Raposo ${ }^{1}$

\section{RESUMO}

O presente artigo se propõe a tecer uma análise acerca das concepções doutrinárias e filosóficas da democracia a fim de relacionar a famigerada democracia autoritária brasileira e os seu conceito, com as concepções de democracia de alguns teóricos que trataram do tema. 0 objetivo geral da pesquisa foi compreender se o sistema que ficou conhecido como democracia autoritária, especialmente durante a era Vargas, de fato pode ser enquadrado em algum conceito de democracia reconhecido pelos teóricos. Para tanto, foram analisados os discursos do filósofo e jurista Hans Kelsen, do filósofo político Norberto Bobbio, bem como do cientista político Robert Dahl, numa construção teórica de natureza bibliográfica, a partir de obras selecionadas, que versassem prioritariamente sobre democracia. Além dos referidos teóricos, as concepções democráticas da era Vargas apresentadas pela professora Angela de Castro Gomes foram igualmente pesquisadas e abordadas. 0 estudo conduz à conclusão que elementos da democracia estão presentes na hipótese, especialmente consideradas as peculiaridades brasileiras.

\section{PALAVRAS-CHAVES}

Democracia. Autoritarismo. Era Vargas. 


\section{ABSTRACT}

This article aims to analyze the doctrinal and philosophical conceptions about democracy in order to relate the famous Brazilian authoritarian democracy, and its concept, to the conceptions of democracy of some theorists who dealt with the theme. The general objective of the research was to understand if the system that became known as authoritarian democracy, especially during the Vargas Era, can in fact be framed in some concept of democracy recognized by theorists. For that, the discourses of the philosopher and jurist Hans Kelsen, of the political philosopher Norberto Bobbio, as well as of the political scientist Robert Dahl, were analyzed in a theoretical construction of a bibliographic nature, based on selected works, which deal primarily with democracy. In addition to these theorists, the democratic conceptions of the Vargas era presented by Professor Angela de Castro Gomes were also researched and approached. The study leads to the conclusion that elements of democracy are present in the hypothesis, especially considering the Brazilian peculiarities.

\section{KEYWORDS}

Democracy. Authoritarianism. Vargas Era.

\section{RESUMEN}

El presente artículo se propone hacer un análisis acerca de las concepciones doctrinales y filosóficas acerca de la democracia a fin de relacionar la famosa democracia autoritaria brasileña y su concepto con las concepciones de democracia de algunos teóricos que trataron del tema. El objetivo general de la investigación fue comprender si el sistema que se conoció como democracia autoritaria, especialmente durante la era Vargas, de hecho puede ser encuadrado en algún concepto de democracia reconocido por los teóricos. Para ello, se analizaron los discursos del filósofo y jurista Hans Kelsen, del filósofo político Norberto Bobbio, así como del científico político Robert Dahl, en una construcción teórica de naturaleza bibliográ-

fica, a partir de obras seleccionadas, que versaran prioritariamente sobre democracia. Además de los referidos teóricos, las concepciones democráticas de la era Vargas presentadas por la profesora Angela de Castro Gomes fueron igualmente investigadas y abordadas. El estudio conduce a la conclusión de que elementos de la democracia están presentes en la hipótesis, especialmente consideradas las peculiaridades brasileñas.

\section{PALABRAS CLAVES}

Democracia; el autoritarismo; Era Vargas; 


\section{INTRODUÇ̄̃̃O}

A história do Brasil é marcada por características políticas e jurídicas que não seguem a mesma lógica ou sequência da historicidade política e jurídica dos países centrais, que chamam a sequência de fatos históricos, por vezes de evolução histórica, política ou jurídica. E essa diferença na historicidade brasileira se deve, em partes, aos regimes autoritários que marcaram uma mudança de paradigma na consolidação do direito e no papel do Estado no nosso país.

A título de ilustração dessa diferença, basta uma simples análise da pirâmide de Marshall (1977) que trata da sequência de consolidação de direitos verificada na Inglaterra. Os estudos do autor concluem que, na Inglaterra, foram introduzidos primeiramente os direitos civis, ainda no século XVIII, um século marcado notadamente pela ruína das estruturas absolutistas a partir da disseminação dos ideais iluministas, processo esse que se inicia já no século XVII.

Sobre essa consolidação de direitos civis, é mister salientar que estes representavam, na prática direitos relacionados à liberdade individual, a exemplo do direito de locomoção, da liberdade de imprensa, de pensamento e de credo, direito à propriedade e acesso à justiça. Nesse ínterim, é relevante observar que o momento histórico da consolidação de direitos civis na Inglaterra refere-se a um momento em que os mesmos eram essenciais à economia de mercado e à liberdade de concorrência e não representavam ameaça alguma ao emergente sistema capitalista.

Na sequência de construção da referida pirâmide, Marshall afirma que, consolidados, os direitos civis, somente um século depois se inicia o processo de consolidação de direitos políticos. Ressalte-se que essa passagem só se dá depois de cem anos de exaustão no exercício dos direitos civis, integrando o rol de direitos ingleses somente no século XIX.

Em relação aos direitos políticos consolidados no período supramencionado, na Inglaterra, vale destacar que esses não se referiam aos direitos políticos como os entendemos hoje, mas se materializavam na expressão do direito de participação no exercício do poder político. Isso se dava por meio da possibilidade de integração de organismo com autoridade política, enquanto membros deste, ou pelo direito de voto.

$O$ século XIX na Inglaterra ainda não fora marcado pelo que hoje entendemos por igualdade política. Isso porque esse momento histórico é marcado por um preconceito de classe que se verifica pela sobreposição das classes superiores sobre as classes inferiores, cerceando exercício do direito de voto por todos.

Por fim, na sequência posta por Marshall, consolidam-se os direitos sociais, mas somente depois de decorridos mais cem anos, pois só integram a tríade de direitos ingleses no século $X X$ que se verificaram quando foram instituídas políticas de concessão de direito ao acesso a serviços educacionais, bem como políticas preocupadas com a economia.

Entretanto, no Brasil essa consolidação de direitos segue o caminho inverso ao da consolidação de direitos individuais na Inglaterra. 0 termo inverso aqui está sendo usado tão somente por questões de cronologia, uma vez que a consolidação de direitos ocorre antes para os ingleses que para os brasileiros. Não se trata, aqui, de considerar que o modelo piramidal de Marshall seja o ideal e isso é um dos pontos a que nos propomos discutir no presente trabalho.

$\mathrm{Na}$ história do nosso país temos garantias de natureza social a partir de 1930, no período conhecido como Era Vargas, a partir de 1945 tem-se uma ampliação de direitos políticos, com uma desaceleração da concretização de direitos sociais, enquanto que os direitos civis buscam extensão e concretização até os dias atuais, segundo análise de José Murilo de Carvatho (2001) em relação à evolução de direitos e concretização da cidadania no Brasil.

Do mesmo modo como aconteceu com a história dos direitos individuais no Brasil, em relação à Inglaterra, as concepções democráticas seguem uma percurso diferente no nosso país e não poderia ser diferente.

Assim como a evolução histórica que conduz a cidadania não possui uma única fórmula, as garantias individuais e coletivas, que conduzem a sistemas democráticos, podem igualmente ser diferentes na história 
de países com realidades muito distintas. Não há como esperar que o Brasil siga o caminho dos países desenvolvidos no seu processo político ou de mudanças jurídicas, pois há países que nunca passaram pelo histórico de colonização baseada na exploração como o Brasil.

Aqui estamos tratando de um país subdesenvolvido cuja colonização não fora de povoamento, como ocorrera nos Estados Unidos da América, bem como não se pode comparar a sequência evolutiva social e política de um país em busca de superar o subdesenvolvimento, condição essa que os países europeus, como a Inglaterra, a que nos referimos, jamais experimentaram.

\section{GOVERNOS AUTORITÁRIOS NA HISTÓRIA DO BRASIL}

A história do Brasil é notadamente marcada por um histórico de políticas autoritárias que, apesar disso, participaram ativamente na consolidação de direitos individuais brasileiros, notadamente dos direitos sociais.

Antes de tratarmos dos momentos históricos de recorrência desses regimes, no Brasil, cabe particularizar o conceito de regime autoritário no histórico brasileiro, para melhor situar os governos caracterizados por tais regimes no país.

No caso do Brasil, quando o termo regime autoritário é utilizado para referir-se a um regime de governo que organizava a sociedade por meio do fortalecimento do Poder Executivo em relação aos demais de modo que esse se sobrepusesse. A finalidade desse fortalecimento, dentre outras, era superar a exclusão política e econômica brasileira no cenário mundial.

Esse período de regime autoritário, no Brasil, remonta, em especial, ao governo pós 1930 e, sobre o referido período, Juliana Rocha Lara (2016, p. 7) postula o seguinte:

0 autoritarismo da década de 30 compunha uma noção de organização da sociedade (que havia vivido na década passada uma série de revoltas) dotando ao Estado um poder Executivo que se sobrepusesse ao demais da nação e também ao Legislativo e ao Judiciário. Tal autoritarismo se opunha fortemente aos elementos liberais que tentavam ser implantados desde a época da Independência em 1822 e reforçados pela constituição de 1891. E ainda, sob a forma de autoritarismo, aparecia a necessidade de unificar o poder no Executivo com fins voltados aos interesses da nação. Por outro lado, a democratização iniciada em 1946, sob a mesma égide do 2 autoritarismo em alguma medida, colocou em pauta o nacionalismo, porém, agora firmado em preceitos democráticos de organização do Estado.

A partir da conceituação de Lara do que houvera sido o autoritarismo no Brasil, percebe-se que els se verifica exatamente no período correspondente a Era Vargas (a partir de 1930), mas esse presidente passa quatro anos no poder, num período posterior ao inicio da democratização, no seu governo que vai de 1951 a 1954 (pós-início da democratização iniciada em 1946).

Além do exposto, cabe destacar que, quanto se trata do tema do autoritarismo no Brasil, dois momentos históricos são associados a essa modalidade de gestão governamental, os períodos entre 1930 - 1945, e entre 1950 - 1954, período conhecido como Era Vargas, bem como os 20 anos que sucederam o golpe civil e militar de 1964 (período, então, compreendido entre 1964 e 1984).

Ou seja, apesar de iniciado o processo de democratização no país, inclusive com a realização de eleições, a nossa história é marcada por um regime autoritário que se consolida por um presidente eleito depois de já iniciada a era democrática no país.

Segundo a professora Dra. Ângela de Castro Gomes, esses foram os momentos que marcaram políticas autoritárias na história do Brasil, vejamos:

De imediato, o que tais eventos trazem à tona para reflexão é a recorrência do autoritarismo na história republicana do país, fato que é acompanhado pelo caráter complexo e ambíguo das duas experiências. Nos dois períodos, apesar de o Brasil conhecer imensas restrições nos terrenos da cidadania civil e política, experimentou políticas públicas que o tornaram mais moderno economicamente, e menos excludente socialmente, embora não menos desigual. A despeito dessas convergências, a forma como a memória nacional reteve essas duas experiências seguiu caminhos muito distintos. (GOMES, 2005, p. 106). 
Verificamos, com isso, que os momentos históricos marcados por políticas de natureza autoritária vão ao encontro da história da consolidação de direitos no Brasil, pois esses regimes tiveram participação direta nas referidas conquistas.

Segundo a autora supracitada, conforme exposto, o autoritarismo brasileiro integra a história da República no país e é durante o referido momento político que se verifica crescimento econômico e uma evolução nas garantias de natureza sociais. Entretanto, essa evolução econômico-social não aparece acompanhada de progressos no campo dos direitos civis e políticos, mas, ao contrário, à custa desses.

Tratada da relação entre garantias sociais e regimes autoritários, no Brasil, se faz necessário dar um passo atrás e analisar o momento constitucional em que nascem os regimes autoritários a que referimos.

A constituição vigente à década de 1930 era a Constituição de 1891, uma constituição caracterizada e influenciada pelos ideais liberais da época da sua promulgação, traz no que se refere a organização estatal administrativa um forte federalismo, sem grandes preocupações com a realização de interesses sociais e coletivos.

Diante do declínio dos próprios ideais fundadores da constituição de 1891, causados inclusive pela crise de 1929, associado aos novos valores da política da Era Vargas, a partir da década de 1930, fez-se necessária a convocação de nova Assembleia Constituinte, para criação de uma Carta coerente com o declínio do liberalismo mundial e com a nova política instaurada, caracterizada por ações de natureza mais interventiva economicamente e mais social.

Sobre essas mudanças de paradigmas constitucionais, Fernanda Xavier da Silva (2010, p. 266) postula o seguinte:

A Constituição de 1934 situa-se no terreno intermediário entre as Cartas de 1891 e 1937, não é tão liberal como a de 1891, nem tão autoritária como a de 1937. Define-se como um texto constitucional híbrido: agrega elementos das principais correntes em debate, consagrando um Estado tipicamente liberal em alguns aspectos e essencialmente autoritário em outros.
Com isso, verifica-se que em termos de suporte constitucional, o regime autoritário brasileiro nasce antes de se ter suas práticas legitimadas constitucionalmente, a posteriori, se respalda em postulados da Constituição Federal de 1934 e tem seus parâmetros de política estatal ainda mais legitimados na Constituição de 1937, que inaugura o Estado Novo da Era Vargas e traz suporte legal que tornam o referido período um período caracterizado por uma política ainda mais autoritária que a do início da década de 1930.

Em relação às alterações verificadas nessa transição da Constituição de 1891 para a Constituição de 1934, observa-se que nessa última, o mesmo Poder Executivo, com atribuições restritas e condicionadas à aprovação do Legislativo, da Carta de 1891 é mantido, o Poder Legislativo ganha ainda mais força e poder de controle do que aquele verificado na Constituição de 1891 há um fortalecimento dos poderes da União em relação ao poder dos estados, numa tentativa de atenuar o excesso de valores federalistas da carta anterior, ao Estado é concedido um maior poder de intervenção e esse passa a regular a educação, o trabalho e a economia (SILVA, 2010, p. 266)

Além das alterações verificadas, o preâmbulo da Constituição de 1934, uma constituição que se estrutura e é promulgada durante um regime autoritário, há menção a regime democrático enquanto regime que assegurará, dentre outros, o bem-estar econômico e social, vejamos:

\begin{abstract}
Nós, os representantes do povo brasileiro, pondo a nossa confiança em Deus, reunidos em Assembleia Nacional Constituinte para organizar um regime democrático, que assegure à Nação a unidade, a liberdade, a justiça e o bem-estar social e econômico, decretamos e promulgamos a seguinte. []. (BRASIL, 1934, on-line)
\end{abstract}

Percebe-se que já no seu texto introdutório a Carta se propõe a organizar o Estado em um regime respaldado nos princípios democráticos, apesar de politicamente organizado sob a forma de regime sustentado por ações autoritárias. Será, então, que se pode falar em democracia, na prática, no período subsequente aos anos 1930, especialmente nos 20 anos de Era Vargas? 
É essa discussão que o artigo se propõe a travar a partir de concepções democráticas teóricas e históricas em relação à história política e aos possíveis avanços e retrocessos da Era Vargas. Vejamos, então, o que é democracia e que tipo de práticas caracterizam aquelas típicas de Estados democráticos.

\section{CONCEPÇÕES TEÓRICAS SOBRE ADEMOCRACIA}

Tratado do período histórico brasileiro que ficou conhecido como regime autoritário, trataremos das concepções teóricas definidoras ou caracterizadoras do regime democrático para, só então, passarmos a exposição da compreensão do que seria ou foi a democracia autoritária da Era Vargas.

Comecemos então pela concepção Kelseniana acerca do que é a democracia, vejamos:

A democracia, no plano da ideia, é uma forma de Estado e de sociedade em que a vontade geral, ou, sem tantas metáforas, a ordem social, é realizada por quem está submetido a esta ordem, isto é, pelo povo. Democracia significa identidade entre governantes e governados, entre sujeito e objeto do poder, governo do povo sobre o povo. (KELSEN, 1993, p. 34).

Nesse sentido, a democracia, para Kelsen é conceituada, considerando-se tanto uma participação direta como uma participação por meio da representação. 0 referido conceito considera que os representantes do povo são escolhidos a partir de um processo de construção identitária entre governantes e governados. Essa pressuposição de existência de uma identidade parte da consideração do que se convencionou chamar de representação perfeita.

De igual modo, Robert Dahl, ao tratar da democracia (chamada por ele de poliarquia, assim entendida como democracia ideal) e do papel da oposição, caracteriza a democracia sempre que haja contínua coerência de ações e atenção do governo às preferências dos seus cidadãos que são considerados politicamente iguais. Para ele, essa igualdade política dos cidadãos deve ser garantida por meio da concessão de oportunidades igualmente plenas, vejamos:
Parto do pressuposto também de que, para um governo continuar sendo responsivo durante certo tempo, às preferências de seus cidadãos, considerados politicamente iguais, todos os cidadãos plenos devem ter oportunidades plenas: 1. De formular suas preferências. 2. De expressar suas preferências a seus concidadãos e ao governo através da ação individual e da coletiva. 3. De ter suas preferências igualmente consideradas na conduta do governo, ou seja, consideradas sem discriminação decorrente do conteúdo ou da fonte da preferência. (DAHL, 1997, p. 110).

Percebe-se que as postulações acerca da democracia, de Robert Dahl levam em consideração a representatividade também de minorias, na medida em que trata da igualdade entre os cidadãos acima de qualquer tipo de discriminação.

Entretanto, havemos de considerar que as concepções de Dahl acima expostas tratam de um modelo ideal e utópico de democracia. 0 próprio autor trata dessa concepção como tal, mas considera que a busca pelo ideal é o mecanismos pelo qual se torna possível garantir gestões governamentais mais e mais democráticas.

Até então, temos como requisitos para a democracia, postos pelos teóricos renomados que trataram do tema, identidade entre representantes e representados, participação, igualdade política dos cidadãos, com garantia de acesso a maiorias e minorias.

Nesse sentido de acesso de minorias se posiciona a professora Marilena Chauí (CHAUÍ, 2012, p. 150), vejamos:

Que significam as ideias de situação e oposição, maioria e minoria, cujas vontades devem ser respeitadas e garantidas pela lei? Elas vão muito além dessa aparência. Significam que a sociedade não é uma comunidade una e indivisa, voltada para o bem comum obtido por consenso, mas, ao contrário, que está internamente dividida, que as divisões são legítimas e devem expressar-se publicamente. Da mesma maneira, as ideias de igualdade e liberdade como direitos civis dos cidadãos vão muito além de sua regulamentação jurídica formal. Significam que os cidadãos são sujeitos de direitos e que, onde tais direitos não existam nem estejam garantidos, tem-se o direito de lutar por eles e exigi-los. É esse o cerne da democracia: a criação de direitos. E por isso mesmo, como criação de direitos, está necessariamente aberta 
aos conflitos e às disputas. Em outras palavras, a democracia é única forma política na qual o conflito é considerado legítimo.

Assim como Dahl, Marilena Chauí parte de concepções democráticas que consideram a existência da diversidade na composição do povo, e, no mesmo sentido, considera que a democracia é um sistema que garante manifestação de maioria e minoria, pois é justamente o conflito que legitima o regime.

Além das considerações de natureza política da democracia, Chauí postula que democracia é elemento determinante de relações sociais. Segundo ela, ao se falar de democracia, não necessariamente a menção estará restrita a regime de governo, mas pode inclusive estar relacionada à sociedade enquanto ente democrático. Vejamos:

\begin{abstract}
Justamente porque opera com o conflito e com a criação de direitos, a democracia não se confina a um setor específico da sociedade no qual a política se realizaria - o Estado --, mas determina a forma das relações sociais e de todas as instituições, ou seja, é o único regime político que é também a forma social da existência coletiva. Ela institui a sociedade democrática. Dizemos, então, que uma sociedade - e não um simples regime de governo - é democrática quando, além de eleições, partidos políticos, divisão dos três poderes da república, distinção entre o público e o privado, respeito à vontade da maioria e das minorias, institui algo mais profundo, que é condição do próprio regime político, ou seja, quando institui direitos e que essa instituição é uma criação social, de tal maneira que a atividade democrática social realiza-se como um poder social que determina, dirige, controla e modifica a ação estatal e o poder dos governantes. (CHAUII, 1012, p. 151).
\end{abstract}

Nesse sentido, Chauí não só supera o conceito de democracia Tocquevilleano, de governo que representa a soberania da maioria, como supera as condições políticas de um governo democrático, quais sejam, existência de eleições e de partidos políticos, divisão dos três poderes da república, distinção entre o público e o privado, bem como respeito à vontade da maioria e também das minorias. Para ela, a existência de uma democracia pressupõe uma criação social de direitos que acaba por consolidar o que ela chama de atividade democrática da sociedade.

Essas concepções apontadas pelos teóricos até aqui, são de natureza distinta das concepções de alguns teóricos mais tradicionais que condicional a existência de uma democracia a caracteres de natureza meramente política. Antes de tratarmos da democracia autoritária em si, entendida essa como a democracia da Era Vargas, cabe ressaltar que na atualidade esses conceitos acerca da democracia ainda aparecem de forma divergente.

Há, ainda, teóricos que defendem concepções democráticas a partir de um ponto de vista mais político, especialmente quando postulam sobre regimes de governos, especialmente ao tratar do caso brasileiro na Era Vargas, a exemplo do professor Leonardo Avritzer (2016, p. 3), segundo o qual:

\begin{abstract}
0 problema da democracia se reduz, mesmo nessas condições, a recriar um ambiente favorável a uma negociação que permita a retirada dos atores autoritários da cena política. Desse modo, o primeiro pressuposto das teorias da transição é que a democracia não é uma situação, e sim um processo que pode ser temporalmente longo. Atores políticos autoritários não abandonam rapidamente suas restrições ao livre funcionamento das instituições políticas. Tampouco eles são, via de regra, derrotados depois de uma mobilização política curta. Pelo contrário, a democracia é em geral alcançada através de um processo longo de negociação, no qual são criadas garantias institucionais recíprocas entre governo e oposição.
\end{abstract}

Nesse sentido, a solução para a conversão de um regime autoritário a um regime democrático perpassa por uma transição que será marcada pela coexistência de ambos os regimes num dado momento. Além disso, Avritzer, assim como Dahl, trazem a oposição como requisito basilar para a existência e consolidação da democracia.

De igual modo, apesar de restringir o conceito a aspectos políticos, as ideias de Avritzer vão ao encontro das postulações de Chauí na medida em que também considera a necessidade de democratização no nível das ações sociais. Para o autor, a democratização é caracterizada por um processo longo de 
compatibilização entre a operação de instituições políticas e os valores de uma esfera societária na qual predominem práticas democráticas.

Para ele, esse longo processo está relacionado à convivência entre duas culturas políticas em que uma se apresenta como semidemocrática, igualmente predominante no nível do sistema de governo e outra democrática, predominante no nível da vida e da sociedade civil.

Segundo Avritzer, o caso do Brasil é uma hipótese sui generis em que não subsiste uma cultura social democrática, por esse motivo, é necessário compreender a própria ação cotidiana dos governantes, demais atores políticos e da administração, vejamos:

\begin{abstract}
No caso de um país como o Brasil, seria pelo menos tão importante quanto a análise sobre a vigência de direitos, entender por que a ação cotidiana de atores políticos relevantes tais como governantes, membros do sistema judiciário e da própria polícia não se orientam pela normatividade existente. Trata-se de compreender que existe uma cultura política não-democrática que se entrelaça com a institucionalidade democrática. As práticas dominantes, neste caso, não são puramente democráticas nem puramente autoritárias. Podemos, portanto, supor a existência de duas culturas políticas e apontar a disputa entre elas no interior do sistema político, na medida em que certos atores defendem a operação de instituições como o governo, o judiciário e a polícia à margem da institucionalidade democrática. (AVRITZER, 2016, p. 5).
\end{abstract}

Percebe-se que as concepções de Avritzer favorecem a ideia da existência de uma democracia autoritária, na medida em que ele trata da possibilidade real de coexistência entre cultura política não-democrática com instituições democráticas.

Segundo o autor, as teorias que tratam da transição para a democracia trabalham com um conceito da democracia como ausência de autoritarismo, isso porque essas teorias postulam que a presença ou a ausência de certos elementos em uma determinada ordem política pode ser empiricamente constatada por meio de institutos como eleições livres e garantia de direitos civis pela Constituição.

O problema envolvido em tal concepção de natureza metodológica, na medida em que essas teorias da tran- sição deixam de lado a forma como os diferentes atores políticos incorporam a institucionalidade vigente e de que modo elas são postas em prática nas suas gestões.

Entretanto, a experiência histórica brasileira aponta para a possibilidade de existência de culturas políticas antagônicas coexistindo, apesar de em constante disputa, dentro de um mesmo sistema, mas deixaremos essa análise dos conceitos e características da democracia apresentados em relação ao caso brasileiro e a possibilidade de existência de uma democracia autoritária para o próximo item.

\section{A DEMOCRACIA AUTORITÁRIA}

Tratados dos conceitos de democracia dos autores selecionados, cabe tratar do que se entende por democracia autoritária para, só então, relacionarmos os temas e conceitos relativos a democracia com o que se entendeu por democracia autoritária no Brasil.

Uma das defensoras da ideia de uma democracia autoritária na Era Vargas é a professora Ângela de Castro Gomes que busca investigar os motivos pelos quais o discurso e as políticas de Vargas que foram construídas no marco do pensamento autoritário, ou seja entre 1920 e 1940, encontraram condições para se estabelecer e para se perpetuar na memória do povo brasileiro.

Ao tratar das hipóteses que favoreceram essas condições, Gomes (2005, p. 107) traz a seguinte:

A primeira diz respeito ao "lugar" que a democracia ocupou na prática e no discurso políticos dos anos 1930. É importante entender que, devido à montante internacional do antiliberalismo, foi possível, para o pensamento autoritário do período, capturar a bandeira da democracia, preenchendo-a de sentidos inteiramente novos e encontrando ampla recepção tanto junto às elites, como nas camadas populares da população. O significado histórico da palavra democracia, particularmente no caso da experiência brasileira, esteve associado à dimensão social e não política, o que permitiu a construção de um conceito aparentemente paradoxal: "democracia autoritária”.

Com isso, resta claro que a adoção de uma política antiliberal coerente com a onda internacional foi a es- 
tratégia que permitiu ao sistema autoritário instaurado no período de adotar a bandeira da democracia para caracterizar, ao menos no nível do discurso, a sua política.

Na realidade, não bastou somente a adoção de uma postura antiliberal para que a política instaurada pudesse se autoproclamar democrática. A instituição de um Estado forte e centralizado que adotava políticas sociais justas e protetivas possibilitou, de igual modo, a convivência entre ideais democráticos e autoritários.

Além disso, nos dizeres da própria autora, na história do Brasil o termo democracia sempre aparece associado a governos que adotam ações voltadas para consolidação de direitos sociais, muito mais que àqueles que buscaram consolidar direitos políticos ou civis.

Em relação às concepções teóricas democráticas apresentadas, podemos verificar que a perpetuação da política varguista na memória e no ideário popular, conforme demonstra a história e conforme afirma a autora, vão ao encontro da concepção kelseniana de existência de identidade entre governantes e governados como pressuposto da democracia.

Obviamente essa análise correlata entre a concepção kelseniana e a história do Brasil se atém a apenas parte da concepção do filósofo, mas serve para demonstrar que na política varguista brasileira, ainda que respaldada em institutos de política autoritária, encontra alguns pontos de encontro com concepções doutrinarias históricas acerca de democracia. Ainda segundo a autora:

Em função da emergência dessa nova forma de autoridade, encarnada na figura pessoal do presidente/Executivo, era impossível e desnecessária a existência de partidos políticos e parlamentos, todos lentos, custosos, ineptos e, sobretudo, órgãos de manifestação dos antagonismos sociais. Algo incompatível com a democracia autoritária, que negava a idéia de uma sociedade fundada no dissenso, postulando a tendência à unidade em todos os aspectos, fossem econômicos, políticos, sociais ou morais. No dizer de Azevedo Amaral, um dos grandes propagandistas desse Estado, "a democracia nova só comporta um único partido: o partido do Estado, que é também o partido da Nação". (GOMES, 2005, p. 112).
Em relação a essa nova forma de autoridade, resta claro que a adoção de políticas que visam cercear o dissenso vai de encontro as concepções democráticas da professora Marilena Chauí, que postula que o conflito é o requisito para a existência de um regime que permite as manifestações de maioria e minoria, e um regime com tal permissividade ou possibilidade é um regime de natureza democrática.

\section{CONCLUSÃO}

Tratado do histórico brasileiro referente aos regimes autoritários, nos propusemos a uma análise acerca das concepções democráticas teóricas para, só então, podermos analisar a possibilidade de existência de um regime fundado em concepções autoritárias e que fosse democrático.

Ao analisar as políticas adotadas pela Era Vargas é possível chegar a algumas conclusões que podem explicar ou justificar a utilização do termo democracia autoritária, por historiadores e cientistas políticos, ao tratar da referida Era.

Se considerarmos as concepções filosóficas de Kelsen, podemos verificar que a característica democrática da identidade entre governantes e governados pode ser verificada na gestão do referido presidente, inclusive isso se comprova ao considerarmos que ele foi também um presidente eleito depois de já ter sido um gestor autoritário de um regime ainda não democrático.

Além desse ponto de encontro, também em relação às concepções de Avritzer, quando trata da transição e coexistência de ambos os regimes por um determinado tempo, verificamos que a Era Vargas pode ser caracterizada dentro desses ideais, na medida em que a primeira fase é caracterizada por um regime que se inicia pós-golpe (1930 a 1945) e, na segunda fase (1941 - 1945) temos eleições diretas com a vitória de Getúlio Vargas.

Com isso, temos que a existência de uma democracia num regime autoritário pode ser possível se considerarmos elementos isolados das concepções 
democráticas, bem como se considerarmos que a compreensão de regime democrático, no Brasil, tem características próprias e que aparece sempre mais associado à dimensão social que política, concepção essa que encontra respaldo em teóricos, como Marilena Chauí e outros que consideram que a concepção de democracia extrapola o âmbito da política.

\section{REFERÊNCIAS}

\section{AVRITZER, Leonardo. Cultura Política, atores}

sociais e democratização: Uma crítica às teorias da transição para a democracia. Disponível em: <http:// www.anpocs.org.br/portal/publicacoes/rbcs_00_28/ rbcs28_09.htm>. Acesso em: 29 abr. 2016. p.3.

\section{BRASIL. Constituição Federal de 1934. Disponível} em: <www.senado.gov.br>. Acesso em: 27 abr. 2016.

CARVALHO, José Murilo de. Cidadania no Brasil: o longo caminho. Rio de Janeiro: Civilização Brasileira, 2001

CHAUÍ, Marilena. Democracia e sociedade autoritária. Comunicação \& Informação, v.15, n.2, p.149-161, jul-dez. 2012.
DAHL, Robert. Poliarquia: Participação e oposição. São Paulo: Universidade de São Paulo, 1997.

GOMES, Ângela de Castro. Autoritarismo e corporativismo no Brasil: o legado de Vargas. REVISTA USP, São Paulo, n.65, p.105-119, mar-maio 2005.

KELSEN, Hans. A democracia. São Paulo: Martins Fontes, 1993

LARA, Juliana Rocha. Autoritarismo e democracia: duas formas de superação do atraso - Caio Prado Junior e Alberto Guerreiro Ramos no Debate. Disponível em: <http://actacientifica.servicioit.cl/ biblioteca/gt/GT13/GT13_RochaLara.pdf>. Acesso em: 28 abr. 2016.

\section{MARSHALL, T.H.A. Cidadania, classe social e status.}

Trad. Meton Porto Gadelha. Rio de Janeiro: Zahar, 1977

SILVA, Fernanda Xavier da. As constituições da Era Vargas: uma abordagem à luz do pensamento autoritário dos anos 30. Política e Sociedade, v.9, n.17, outubro de 2010. p.266
Recebido em: 13 de novembro de 2017 Avaliado em: 29 de julho de 2018 Aceito em : 30 de julho de 2018
1 Doutoranda em Direito pela Universidade de São Paulo; Mestre em Direito Político e Econômico pela Universidade Presbiteriana Mackenzie; Mestre em Letras pela Universidade Federal de Sergipe. E-mail: fernandagurgel@msn.com 